\title{
Insecticide-treated durable wall lining (ITWL): future prospects for control of malaria and other vector-borne diseases
}

\author{
Louisa A. Messenger ${ }^{*}$ and Mark Rowland
}

\begin{abstract}
While long-lasting insecticidal nets (LLINs) and indoor residual spraying (IRS) are the cornerstones of malaria vector control throughout sub-Saharan Africa, there is an urgent need for the development of novel insecticide delivery mechanisms to sustain and consolidate gains in disease reduction and to transition towards malaria elimination and eradication. Insecticide-treated durable wall lining (ITWL) may represent a new paradigm for malaria control as a potential complementary or alternate longer-lasting intervention to IRS. ITWL can be attached to inner house walls, remain efficacious over multiple years and overcome some of the operational constraints of first-line control strategies, specifically nightly behavioural compliance required of LLINs and re-current costs and user fatigue associated with IRS campaigns. Initial experimental hut trials of insecticide-treated plastic sheeting reported promising results, achieving high levels of vector mortality, deterrence and blood-feeding inhibition, particularly when combined with LLINs. Two generations of commercial ITWL have been manufactured to date containing either pyrethroid or non-pyrethroid formulations. While some Phase III trials of these products have demonstrated reductions in malaria incidence, further large-scale evidence is still required before operational implementation of ITWL can be considered either in a programmatic or more targeted community context. Qualitative studies of ITWL have identified aesthetic value and observable entomological efficacy as key determinants of household acceptability. However, concerns have been raised regarding installation feasibility and anticipated cost-effectiveness. This paper critically reviews ITWL as both a putative mechanism of house improvement or more conventional intervention and discusses its future prospects as a method for controlling malaria and other vector-borne diseases.
\end{abstract}

Keywords: Insecticide-treated durable wall lining, Malaria, Leishmaniasis, Chagas disease, Vector control, Insecticide resistance

\section{Background}

In recent years considerable reductions in global malaria burden have been achieved by scaling-up key diagnostic, treatment and preventative measures [1]. Long-lasting insecticidal nets (LLINs) and indoor residual spraying (IRS) remain the cornerstones of malaria vector control, both targeting indoor feeding and resting mosquito vector populations [2-5]. Long-term effectiveness of these strategies is currently under threat from widespread emergence of insecticide resistance to pyrethroid LLINs

${ }^{*}$ Correspondence: louisa.messenger@lshtm.ac.uk Department of Disease Control, Faculty of Infectious Tropical Diseases, London School of Hygiene and Tropical Medicine, London, UK
$[6,7]$, as well as to other chemical classes used for IRS $[8,9]$. Furthermore, maintaining high coverage at the community-level of either intervention can be operationally challenging. Universal coverage (UC) campaigns of LLINs have been adopted as the standard of care by most National Malaria Control Programmes (NMCPs) [1]; however, net usage is known to decline during hot seasons [10-12], and LLIN efficacy and durability under field conditions $[13,14]$ and rates of household attrition are also of increasing concern $[15,16]$. In some epidemiological settings, IRS can be highly effective $[1,17]$ but the short residual activities of most insecticide formulations [18] render it logistically demanding and economically unsustainable for many endemic countries [19]. To 
maintain and consolidate gains and to transition towards malaria elimination and eradication [20], there is a growing impetus to develop alternate or complementary interventions [4, 5, 21], novel insecticide classes [22, 23], combinations $[24,25]$, formulations $[26,27]$ and costeffective, scalable mechanisms of delivery [28-30], as well as to evaluate a potential role for concurrent housing improvement in disease control [31-33].

\section{Initial experimental development and evaluation of insecticide-treated housing materials}

Insecticide treatment of house or shelter materials was first pioneered as a method to control malaria during humanitarian emergencies in countries affected by war [34-37]. Impregnation of utilitarian tents or tarpaulins with deltamethrin was intended to circumvent the logistical difficulties of achieving high coverage with IRS or insecticide-treated nets (ITNs), producing high rates of mosquito mortality in experimental platform studies and pilot malaria control projects in Pakistan [35-37]. Early experimental hut evaluations of pyrethroid (deltamethrin or permethrin) and non-pyrethroid (pirimiphos-methyl, organophosphate or bendiocarb, carbamate) treated plastic sheeting (ITPS) as an interior wall liner, indicated that this intervention functions in a similar manner to IRS against host-seeking vectors entering indoors and alighting on walls either before or after blood-feeding, or if blocked from feeding by a mosquito net (Table 1). Only limited personal protection from biting was observed when ITPS was evaluated alone, suggesting disease control would instead be achieved through a 'mass effect' on vector density and longevity at the community-level [38, 41, 42, 46-48]. Depending upon the excito-repellant properties of different insecticides used to treat ITPS, some studies also reported increased deterrence rates and exophily among susceptible mosquito populations, demonstrating the potential to directly interrupt humanvector contact, further contributing to a reduction in malaria transmission $[38,41,42,46]$. For the majority of entomological parameters, ITPS efficacy was correlated with intervention surface area, with increasing coverage affording higher rates of mortality, deterrence and bloodfeeding inhibition $[38,39,46]$.

\section{Initial community-level trials of insecticide-treated housing materials}

Following preliminary trials of experimentally-treated plastic materials (Table 1), commercial ITPS (ZeroFly ${ }^{\circledR}$ ) was originally produced by Vestergaard Frandsen (Switzerland) as high density laminated polyethylene sheets containing deltamethrin $\left(55 \mathrm{mg} / \mathrm{m}^{2}\right)$. Based on LLIN technology, the insecticide is incorporated into the polymer during manufacture and diffuses to the surface slowly, in a controlled fashion, acting as a long-lasting insecticide reservoir. Initial community-level evaluations of ZeroFly ${ }^{\circledR}$ ITPS in temporary labour shelters and villages in India [40, 43] and among displaced populations in Sierra Leone [44] and Angola [45] supported the entomological outcomes reported by experimental hut trials, achieving significant reductions in malaria incidence (Table 2). Similar observations of the impact of coverage on intervention effectiveness were observed in Sierra Leone, where protective efficacy from malaria improved from 15 to $60 \%$ when ITPS coverage increased from ceiling only to include all four tent walls [44]. However, when carbamate-treated ITPS was evaluated in combination with UC or targeted LLIN distribution among rural houses in Benin, no additional malaria protection was reported, potentially attributable to limited wall coverage (only the upper thirds of walls were covered due to insecticide safety concerns), and the short residual activity of a single treatment of bendiocarb [21].

\section{Commercial development of insecticide-treated housing materials}

The promising results demonstrated by ITPS stimulated an interest in developing a long-lasting, sustainable, community-level version for permanent use in malaria endemic settings. Such a material would offer the prospect of a novel system of insecticide delivery, which could be more residual than IRS, provide a more uniform covering of the wall with insecticide and potentially improve the interior appearance of traditional dwellings, particularly in rural areas. To identify an acceptable wall lining material, among urban and rural houses in Angola and Nigeria, three deltamethrin-treated prototypes (polyethylene woven shade cloth, laminated polyethylene plastic sheeting $\left(\mathrm{ZeroFly}^{\circledR}\right.$ ) and polyester netting (PermaNet ${ }^{\circledR}$ 2.0) were assessed for their levels of household acceptability, installation feasibility and willingness to pay (Fig. 1) [52]. Rural participants highly favoured the concept of a wall lining for malaria control because of its observable impact on mosquitoes and other nuisance insects and perceived decorative value, given an existing predilection for house decorations. Of the prototype materials, polyethylene shade cloth was the most popular because of its ease of installation and resemblance to local materials. Based on these pilot field trials, the original iteration of insecticide-treated durable wall lining (henceforth ITWL; referred in previous publications as 'durable lining' or 'DL') was produced in the form of high density polyethylene woven sheets containing deltamethrin (ZeroVector ${ }^{\circledR} ; 175 \mathrm{mg} / \mathrm{m}^{2}$ ) (Fig. 1). Initial smallscale studies across multiple African and Asian countries demonstrated consistently high levels of user acceptability, entomological efficacy and no significant loss of 


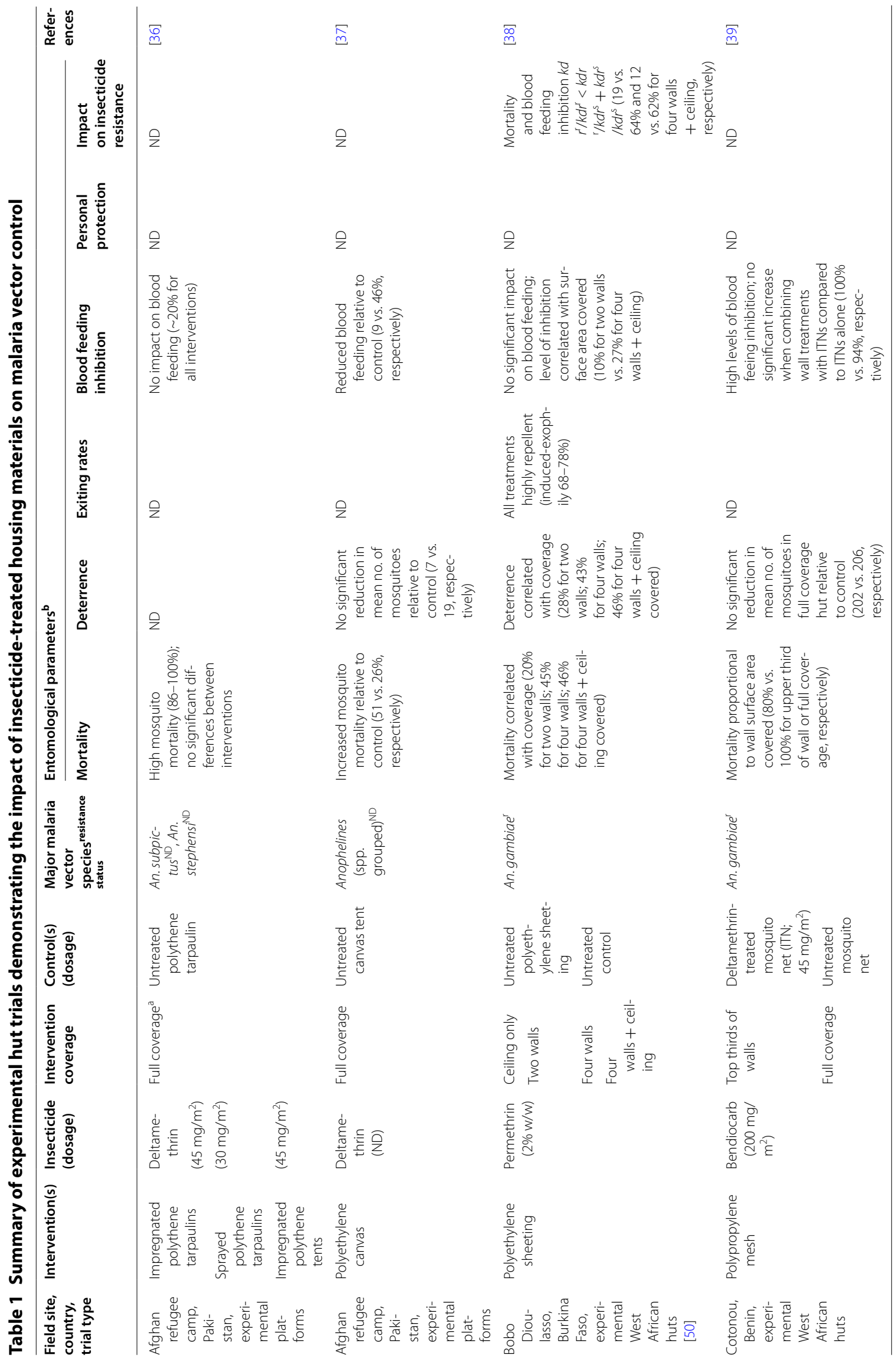




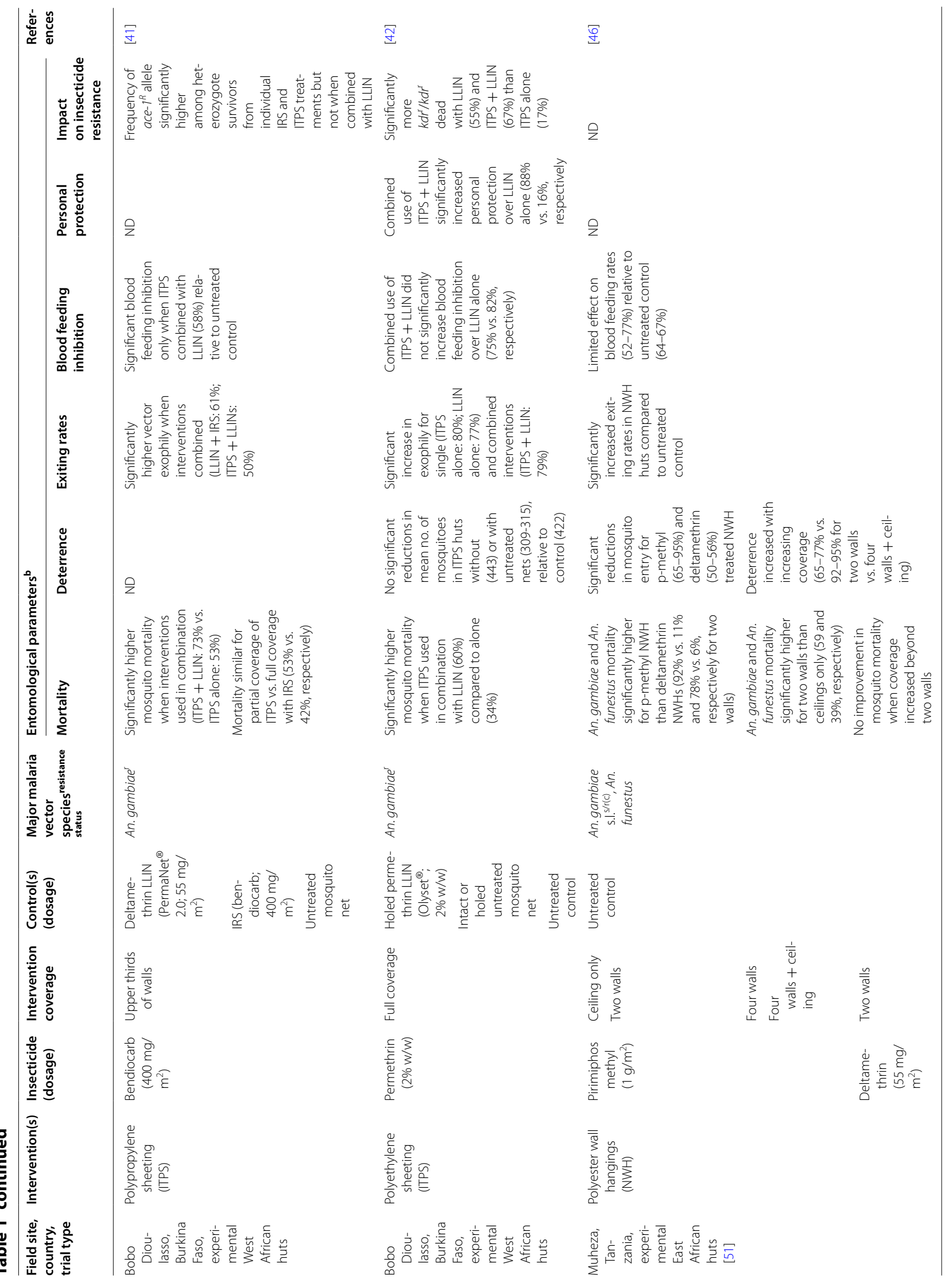




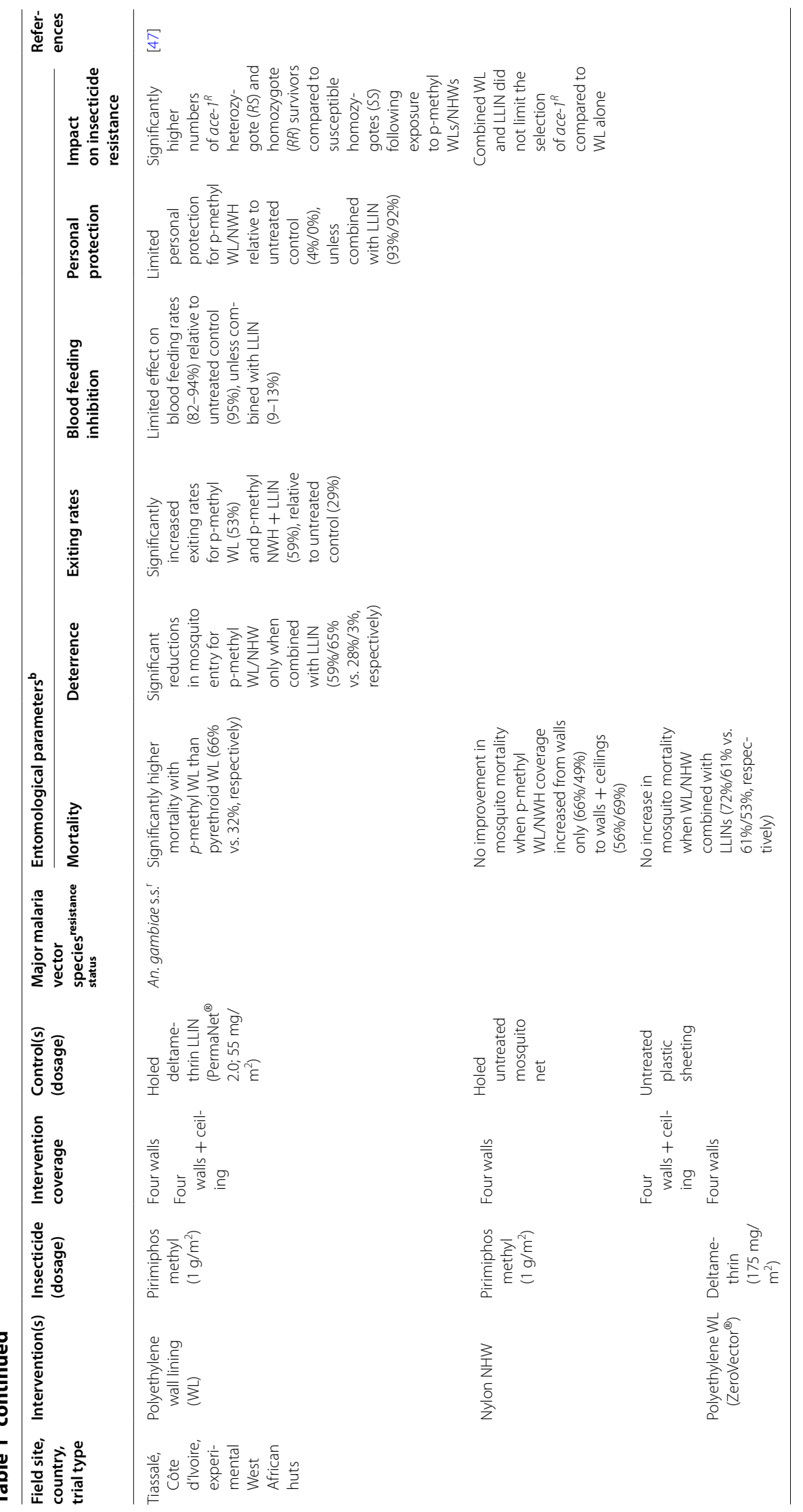




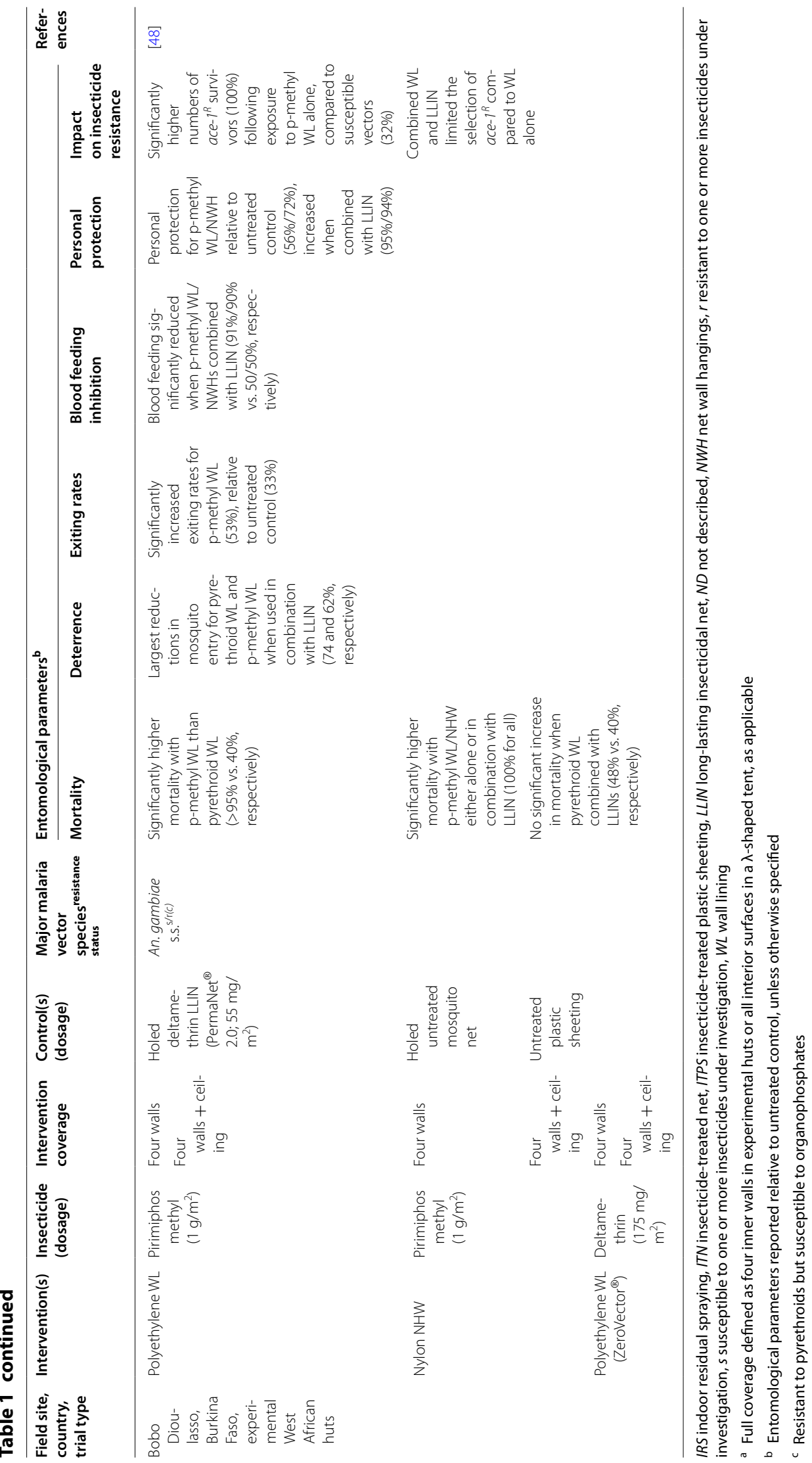




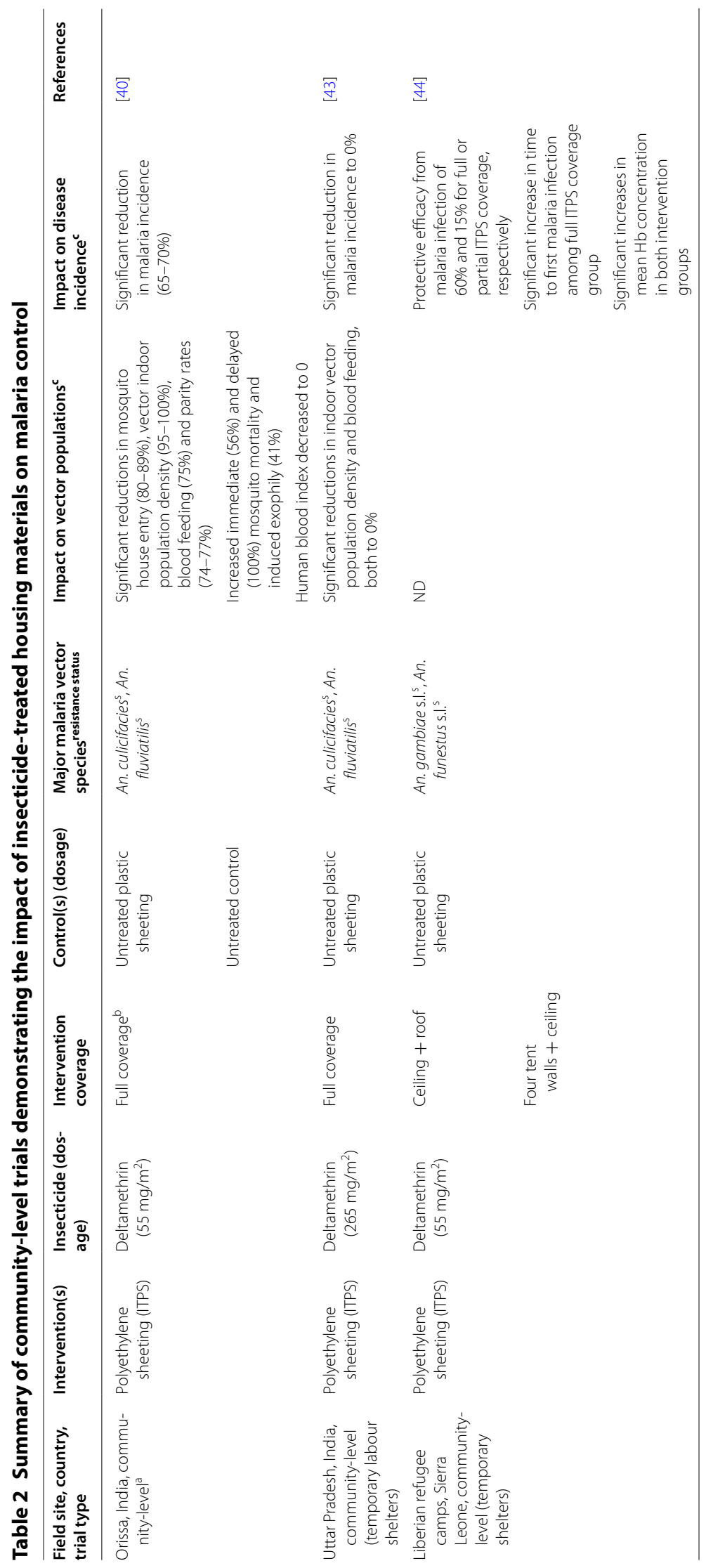




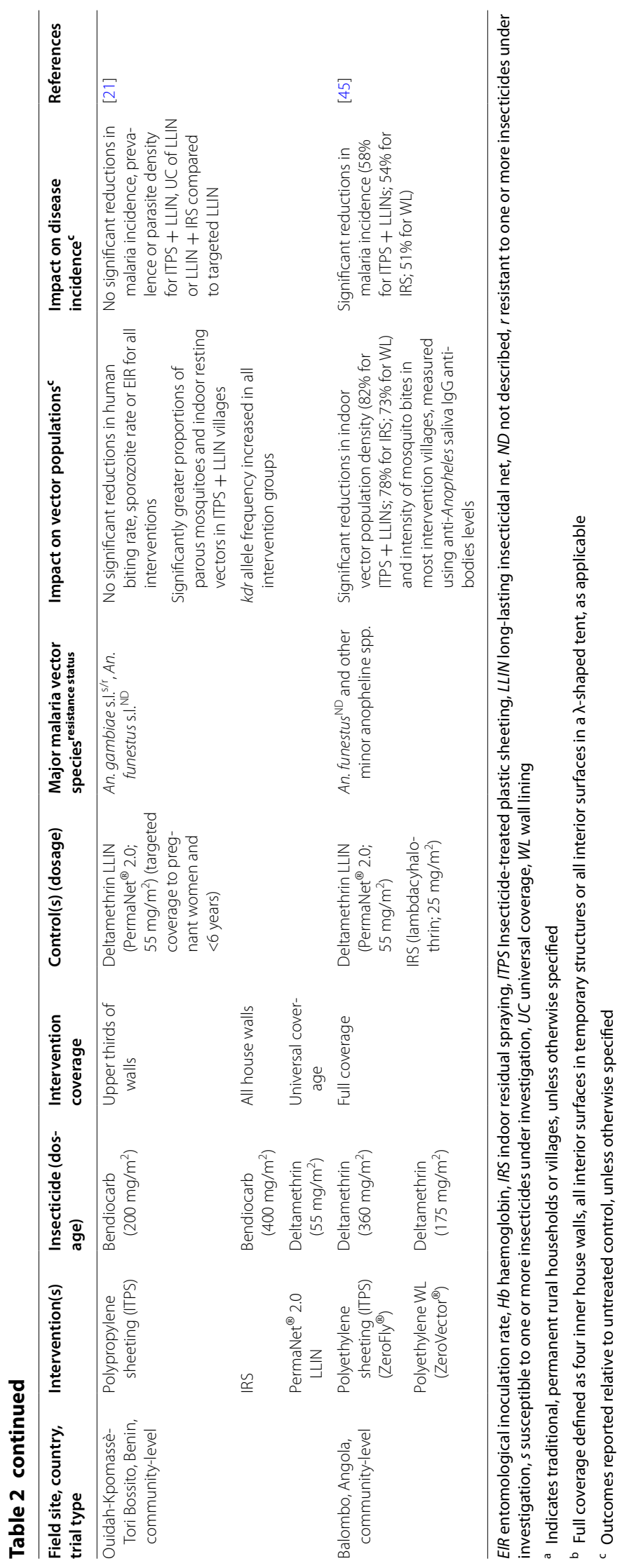



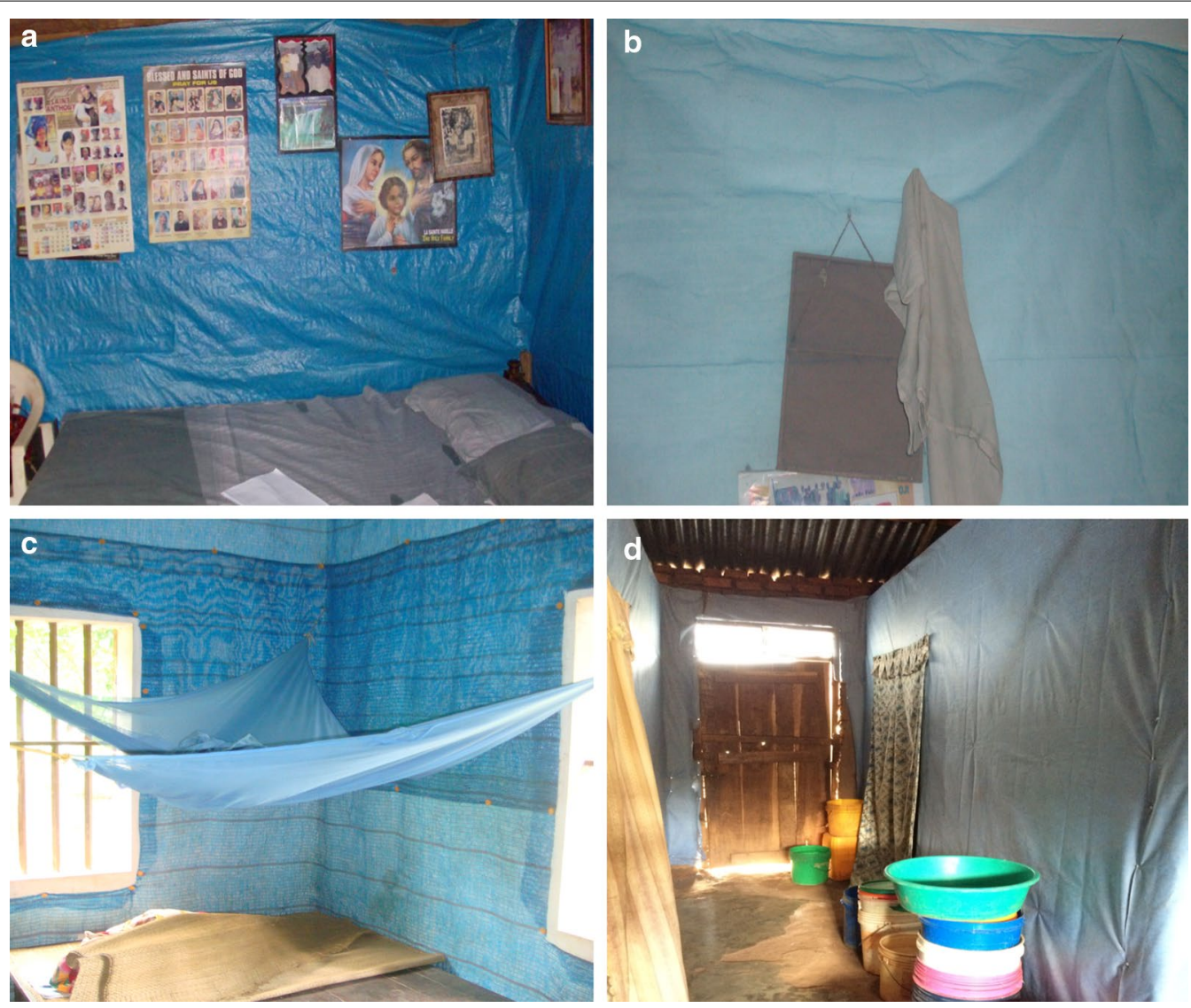

Fig. 1 Commercial ITWL products. a Polyethylene plastic sheeting $\left(\right.$ ZeroFly $\left.{ }^{\circledR}\right)$. b Polyester netting $\left(\right.$ PermaNet $\left.{ }^{\circledR} 2.0\right)$. c Polyethylene woven shade cloth $\left(\right.$ ZeroVector $\left.^{\circledR}\right)$. d Polypropylene non-woven fabric (PermaNet ${ }^{\circledR}$ Lining)

insecticidal activity over 1 year of household use [53, 54]. However, no phase III evaluation of this product was ever conducted due to the emergence of widespread pyrethroid resistance among vector populations across subSaharan Africa $[6,7]$. In response, the latest generation of commercial ITWL (PermaNet ${ }^{\circledR}$ Lining; Vestergaard Frandsen) was designed as a non-woven, high density polypropylene fabric containing a proprietary mixture of two non-pyrethroid insecticides (abamectin $0.25 \%$ and fenpyroximate $1 \%$ ), to potentially mitigate insecticide resistance (Fig. 1). This product is currently the subject of an ongoing cluster-randomized controlled trial in an area of pyrethroid-resistance in rural North-East Tanzania, in comparison with UC of LLINs, assessing whether this version of ITWL can provide additional protection from malaria [55].

\section{A potential role for insecticide-treated housing materials in resistance management}

Now that pyrethroid resistance is pervasive across Africa, there has been a policy shift away from pyrethroid IRS towards the restriction of this insecticide class to LLINs for which there are currently no approved alternatives [49]. Because the 'mode of action' of ITWL is analogous to a long-lasting IRS and Africa has become a LLIN using continent, the combined use of ITWL and LLINs may have resistance management potential. In areas with pyrethroid-resistant vector populations, the role of ITPS/ ITWL plus LLINs or IRS to mitigate selection of resistant genotypes was investigated in experimental settings. Theoretically, combining interventions with different active ingredients can improve vector control because mosquitoes which are resistant to the insecticide in one intervention may be susceptible to the chemical class contained in the other. Several studies demonstrated that the combination of ITPS and LLINs can increase mortality, blood feeding inhibition and personal protection, the latter largely provided by LLINs, [41, 48], but that ITPS, when used alone, may select for resistant vectors, as evidenced by higher proportions of mosquitoes carrying resistance genes surviving in ITPS-treated huts [41, $42,47,48]$. The difference in selection pressures likely reflects the different stages of the gonotrophic cycle, which ITPS and LLINs disrupt. Host-seeking mosquitoes 
upon encountering a LLIN may persist in their attempt to feed, by either making more flights between treated walls and the netted sleeper, increasing the chances of exposure to a lethal dose of the non-pyrethroid insecticide in the ITPS, or from the pyrethroid LLIN by probing for longer on the net surface, particularly if they have a degree of pyrethroid resistance and are less irritated. In this scenario, a proportion of females resistant to either insecticide would be killed. However, in the absence of a LLIN, once successfully fed, females become relatively quiescent and alight on the walls where differential selection, between susceptible and resistant genotypes, to the ITPS insecticide occurs. This explanation is plausible in Burkina Faso where resistance to the ITPS insecticide was rare and was selected by the ITPS when applied alone but not when ITPS was combined with LLINs [48]. However, in Côte d'Ivoire, where the baseline frequency of resistance to the organophosphate-containing ITPS was higher and where multiple resistance mechanisms to this chemical class were present [56], the same combination of interventions, as applied in Burkina Faso, did not significantly increase mosquito mortality rate over ITPS or LLIN alone, and did not limit the selection of resistant genotypes [47]. Hence the resistance management potential of combining ITWL and LLIN is not a foregone conclusion but appears to depend on the mechanisms and frequency of resistance already present in a locality or country as a result of previous selective pressures. These studies caution the application of ITWL in areas with resistant vectors in the absence of high community-level net coverage to safeguard continuing personal protection afforded by LLINs.

\section{Key determinants of community-level ITWL acceptability}

The principal rationales of ITWL, which render it an attractive alternative to IRS, are its longevity, provision of protection to LLIN non-compliers and potential to overcome the user and donor fatigue associated with repeated rounds of spraying. Consequently, the majority of latterly ITWL studies have focused on identifying key determinants of acceptability and operational feasibility of implementing this intervention in endemic areas (Table 3). In general, themes of decorative value, ownership prestige, few noticeable adverse events and immediate and sustained entomological efficacy have all been reported to positively affect participant receptivity and compliance $[52,53,57]$. The relative influence of these factors on levels of community acceptability varies between study sites. In Angola, despite householders initially commending ITWL for improving their house aesthetics, once the material was considered ineffectual, the majority of participants removed theirs [52]. By contrast, in a multi-centre trial, respondents unanimously reported wanting to keep their ITWL even if it had no impact at all on mosquito populations or other nuisance insects [53]. Other attractive features of ITWL described in these studies include, the concept of a single intervention that would alleviate the daily inconvenience of multiple control measures, its role as an additional building material to block holes in walls, reduce draughts, noise and dust, and how easily it can be removed and re-installed when certain communities participate in annual house renovations, particularly re-smearing walls with mud during festive periods $[57,59]$. Common aspects of ITWL which were causes for concern amongst householders were its impact on house ventilation, possible flammability, fragility, especially in the context of damage caused by children, and how long-term exposure to smoke from internal, unventilated fires may affect its aesthetics, durability and insecticidal efficacy. Finally, one more unexpected, negative outcome reported in several sites was the collateral cessation of LLIN use and other methods of disease control, as ITWL was perceived to be either a sufficient or superior malaria prevention strategy [57-59]. These observations clearly demonstrate that application of this intervention must be accompanied by re-iterative community sensitization to sustain the use of all available control measures.

\section{Future prospects of ITWL for malaria control: control intervention or method of house improvement?}

In the absence of unequivocal evidence to support ITWL as an alternate control measure to IRS, the questions remain, how will this intervention function to reduce malaria, in what epidemiological situation will it warrant implementation and how will it be executed to scale? There is increasing evidence to support a crucial role for housing improvement in malaria control [31-33, 60, 61]. It can be envisaged that ITWL could act as an effective and insecticidal method of house, and in particular, eave screening, if affixed to the base of the roof or ceiling and proven to have long-term durability. However, with concomitant housing, social and economic development, will potential communities still accept ITWL as readily based on its perceived aesthetics? Reports from more affluent urban residents in Nigeria suggest this might not be the case [50]. Alternatively, even if ITWL were to be proven effective and applied in a similar manner to IRS, there are considerable implications for installation logistics. Previously, ITWL has been primarily installed using locallysourced nails, often covered with plastic caps to improve wall grip [62]. Installation time, which accounts for time taken to attach the material to house walls, as well as preparation (removal of all household and wall items) 


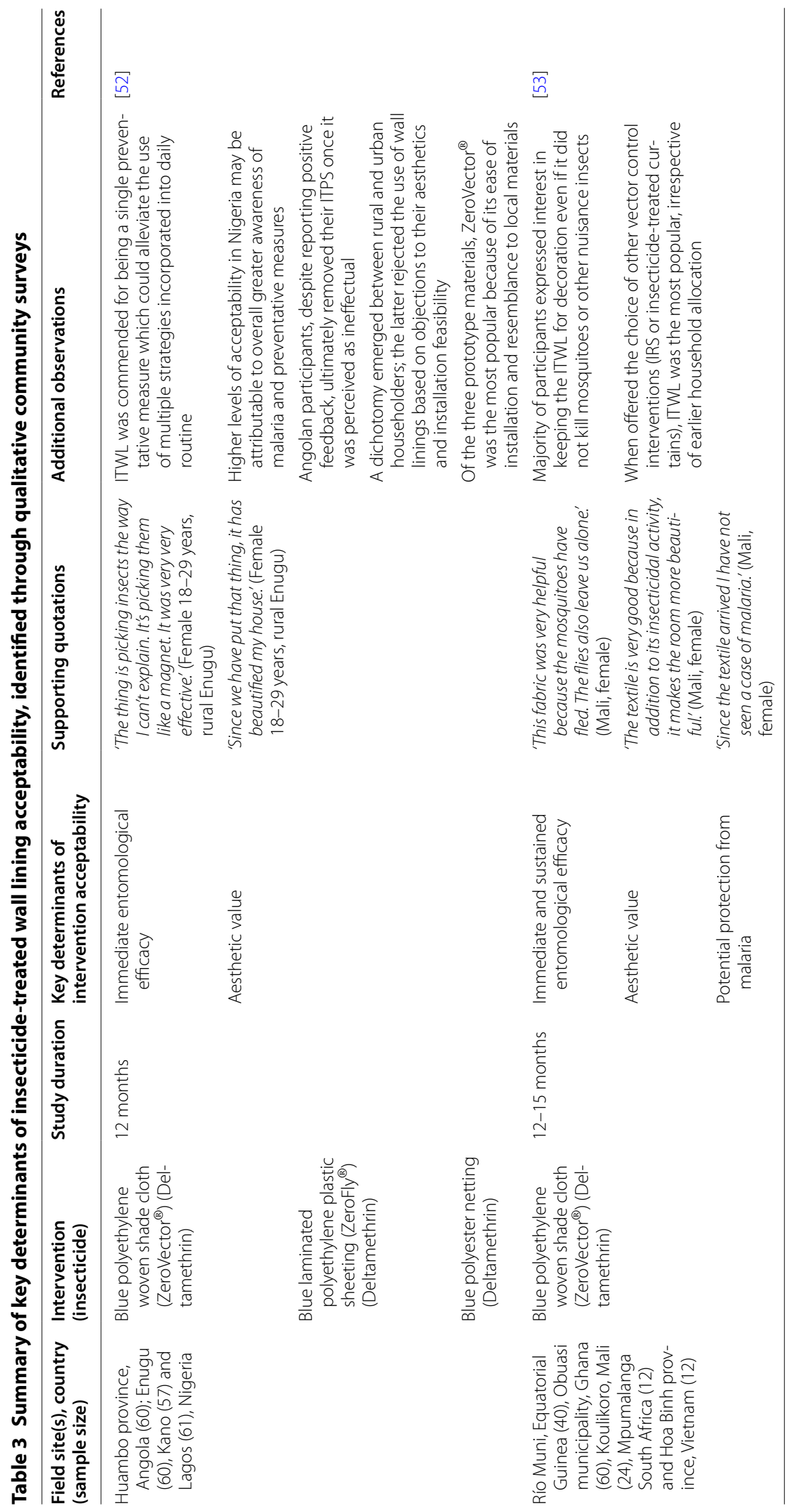




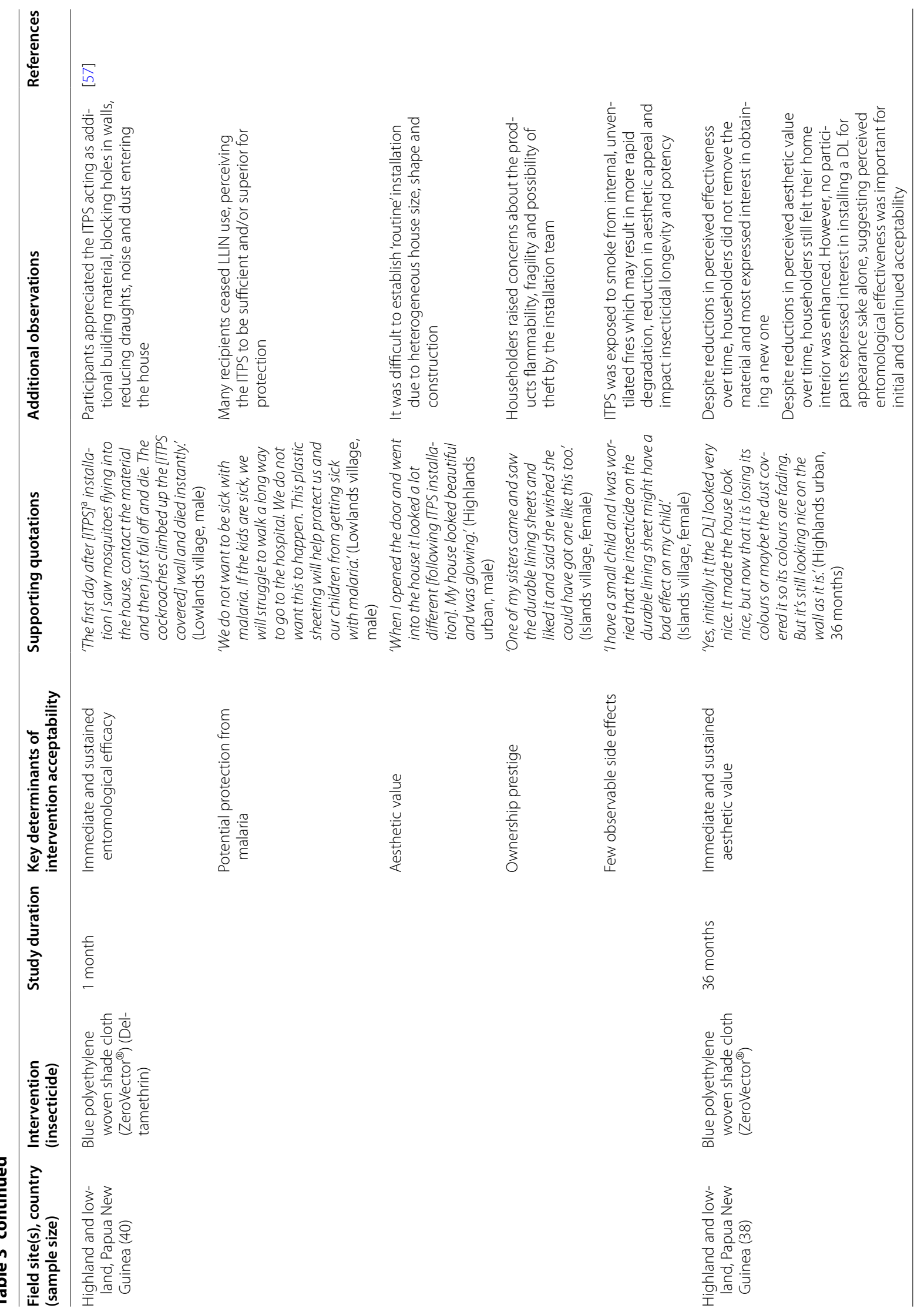




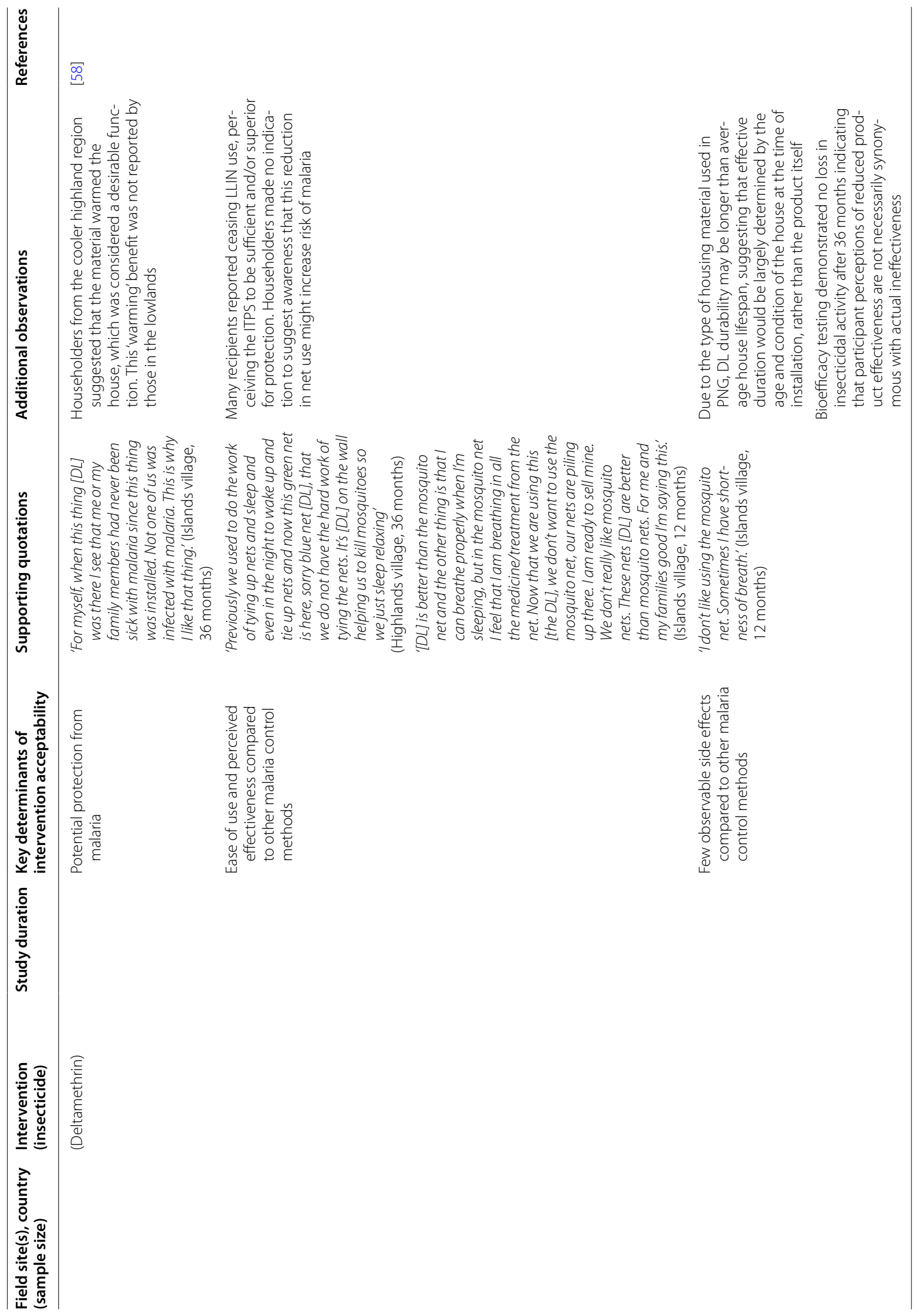




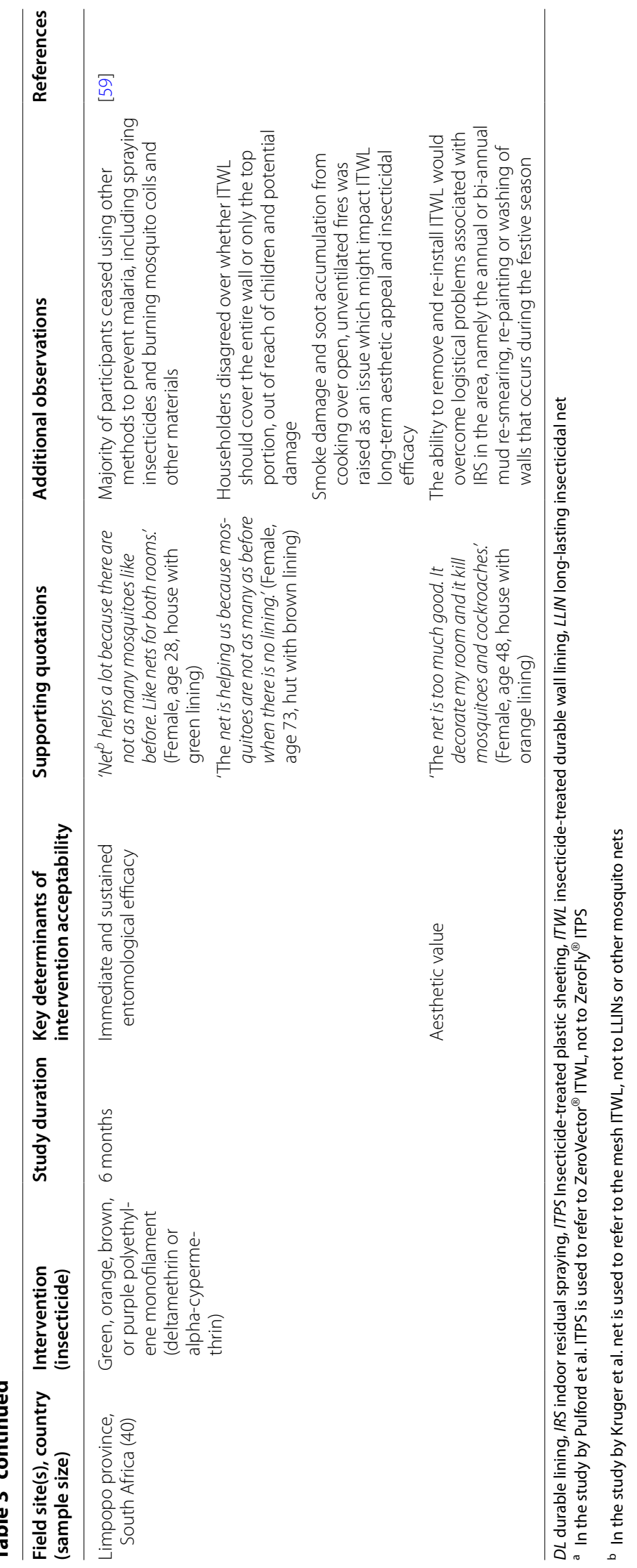


and clean-up, is largely correlated with overall house size, construction and number of rooms to be covered. From an economic perspective, lengthy or highly variable installation times, among communities containing heterogeneous house constructions, will have repercussions on intervention cost-effectiveness, potentially requiring financing mechanisms that many African countries lack [63]. By comparison to IRS, which is estimated at as little as $\$ 5$ for pyrethroid (ICON ${ }^{\mathrm{TM}}$ lambdacyhalothrin capsule suspensions) to $\$ 23.50$ for organophosphate sachets (Actellic CS 3000) [64], ITWL installation also requires the purchase, temporary storage and transportation of large ITWL rolls (measuring $2.4 \times 210 \mathrm{~m}$ and weighing $40 \mathrm{~kg}$ each), supporting fixings and resources (e.g. nails, hammers, tape measures, step ladders etc.), often to remote and inaccessible locations. In this scenario, unlike IRS, the cost of contracting and deploying specialist installation teams by NMCPs would likely be financially prohibitive.

Other, as yet unanswered issues, include just how much of a wall or house must be covered with ITWL to impact disease transmission, could ITWL coverage be restricted to sleeping rooms with only limited loss of effectiveness and how can high quality intervention installation and community maintenance be ensured and monitored, as ITWL is expected to function for multiple years, without external upkeep or interference. Moreover, should ITWL durability be assessed in terms of overall householdlevel coverage, given it will likely impact malaria transmission like IRS, through a reduction in overall vector population density, or because of its long-lasting LLINlike properties, will the formation of holes from daily household wear and tear also impact efficacy? Given its higher cost, ITWL is unlikely to be considered for widespread programmatic implementation but instead may be more appropriate as a method to control malaria in areas where pyrethroid-resistant vectors predominate, or to reduce epidemic hot spots of transmission [20,65]. Unlike vertical IRS programmes and mass LLIN distributions, potential delivery systems for ITWL could utilize a combination of social mobilization and microfinancing or subsidization, designating direct responsibility of installation and maintenance to community members.

\section{Future prospects of ITWL for control of other vector-borne diseases}

To date, ITWL has primarily been evaluated for its effectiveness as a malaria control strategy. However, there are fundamental features underlying the biology of other vector-borne diseases where ITWL could also play a critical role in interrupting disease transmission. Leishmaniasis remains an important neglected tropical disease with an estimated 350 million individuals at risk worldwide [66]. Vector management is one of the principal disease control strategies, targeting putative resting sites of phlebotomine sand flies, usually with IRS [67]. In addition to all of the aforementioned limitations of IRS, because some vector species display crepuscular feeding activities, LLINs can also be ineffective in these endemic countries [68]. Recently, the efficacy of ZeroVector ${ }^{\circledR}$ ITWL was investigated in a multi-centre study in Bangladesh, India and Nepal, demonstrating high levels of sand fly mortality and household acceptability and decreases in vector density over 12 months of household use [69, 70]. However, no epidemiological endpoints to assess the impact of ITWL on incidences of visceral leishmaniasis were measured, indicating further evaluations of this intervention are still needed. ITWL also warrants consideration as a supplementary intervention to control Chagas disease, which is transmitted by highly domiciliated triatomine bug vectors, inhabiting cracks in the walls of rural adobe houses across Latin America [71]. Despite achieving substantial reductions in disease incidence through historic large-scale trans-national IRS campaigns, active transmission persists, particularly in the Gran Chaco, where rapid domestic re-infestation abounds and insecticide resistance is increasing; both of which are exacerbated by decentralized regional control efforts in areas of recurrent political, social and economic instability [72]. While ITWL has yet to be directly evaluated against Chagas disease, organophosphate and juvenile growth hormone containing insecticidal vinyl paints (Inesfly $5 \mathrm{~A} \mathrm{IGR}^{\circledR}$ ), based on similar principles to ITWL, have thus far reported encouraging experimental results $[73,74]$ and long-term reductions in levels of household triatomine infestation $[75,76]$.

\section{Conclusions}

Insecticide-treated durable wall lining (ITWL) is a novel method of vector control, which when attached to inner house walls remains efficacious over multiple years and can circumvent some of the logistical constraints associated with first-line control strategies. To date, there is substantial phase II data indicating ITWL can impact malaria vector populations, with complete wall coverage affording the highest rates of mosquito mortality, deterrence and blood-feeding inhibition in experimental hut trials. However, there is currently limited Phase III evidence to support operational implementation of ITWL either as a control intervention in a programmatic context or as an insecticidal method of house improvement or eave screening. While aesthetic value and observable entomological efficacy are key determinants of acceptability, additional studies are still required to determine feasible and cost-effective financing mechanisms of installation to sustain ITWL durability during long-term 
field use. Further large-scale community-level trials are warranted to support the development and evaluation of ITWL as a potential alternate control strategy for malaria and other vector-borne diseases.

\author{
Abbreviations \\ CRT: cluster-randomized controlled trial; CS: capsule suspension; DL: durable \\ lining; IGR: insect growth regulator; ITN: insecticide-treated net; IRS: indoor \\ residual spraying; ITPS: insecticide-treated plastic sheeting; ITWL: insecticide- \\ treated durable wall lining; LLIN: long-lasting insecticidal net; NMCP: National \\ Malaria Control Programme; UC: universal coverage.
}

\section{Authors' contributions}

LAM and MR co-drafted the manuscript. Both authors read and approved the final manuscript.

\section{Acknowledgements}

LAM and MR are supported by the Malaria Centre of the London School of Hygiene and Tropical Medicine (http://malaria.Ishtm.ac.uk).

\section{Competing interests}

The authors declare that they have no competing interests.

\section{Publisher's Note}

Springer Nature remains neutral with regard to jurisdictional claims in published maps and institutional affiliations.

Received: 21 February 2017 Accepted: 15 May 2017

Published online: 22 May 2017

\section{References}

1. WHO. World malaria report 2014. Geneva: World Health Organization; 2014

2. Lengeler $C$. Insecticide-treated bed nets and curtains for preventing malaria. Cochrane Database Syst Rev. 2004;2:CD000363.

3. Pluess B, Tanser FC, Lengeler C, Sharp BL. Indoor residual spraying for preventing malaria. Cochrane Database Syst Rev. 2010:4:CD006657.

4. West PA, Protopopoff N, Wright A, Kivaju Z, Tigererwa R, Mosha FW, et al. Indoor residual spraying in combination with insecticide-treated nets compared to insecticide-treated nets alone for protection against malaria: a cluster randomised trial in Tanzania. PLoS Med. 2014;11:e1001630.

5. Pinder M, Jawara M, Jarju LB, Salami K, Jeffries D, Adiamoh M, et al. Efficacy of indoor residual spraying with dichlorodiphenyltrichloroethane against malaria in Gambian communities with high usage of long-lasting insecticidal mosquito nets: a cluster-randomised controlled trial. Lancet. 2015;385:1436-46.

6. Ranson H, N'Guessan R, Lines J, Moiroux N, Nkuni Z, Corbel V. Pyrethroid resistance in African anopheline mosquitoes: what are the implications for malaria control? Trends Parasitol. 2011;27:91-8.

7. Strode C, Donegan S, Garner P, Enayati AA, Hemingway J. The impact of pyrethroid resistance on the efficacy of insecticide-treated bed nets against African anopheline mosquitoes: systematic review and metaanalysis. PLoS Med. 2014;11:e1001619.

8. Protopopoff N, Matowo J, Malima R, Kavishe R, Kaaya R, Wright A, et al. High level of resistance in the mosquito Anopheles gambiae to pyrethroid insecticides and reduced susceptibility to bendiocarb in north-western Tanzania. Malar J. 2013;12:149.

9. Riveron JM, Chiumia M, Menze BD, Barnes KG, Irving H, Ibrahim SS, et al. Rise of multiple insecticide resistance in Anopheles funestus in Malawi: a major concern for malaria vector control. Malar J. 2015;14:344.

10. Koenker HM, Loll D, Rweyemamu D, Ali AS. A good night's sleep and the habit of net use: perceptions of risk and reasons for bed net use in Bukoba and Zanzibar. Malar J. 2013;12:203.
11. Frey C, Traore C, De Allegri M, Kouyate B, Muller O. Compliance of young children with ITN protection in rural Burkina Faso. Malar J. 2006;5:70.

12. Toé LP, Skovmand O, Dabire KR, Diabate A, Diallo Y, Guiguemde TR, et al. Decreased motivation in the use of insecticide-treated nets in a malaria endemic area in Burkina Faso. Malar J. 2009:8:175.

13. Gnanguenon V, Azondekon R, Oke-Agbo F, Beach R, Akogbeto M. Durability assessment results suggest a serviceable life of two, rather than three, years for the current long-lasting insecticidal (mosquito) net (LLIN) intervention in Benin. BMC Infect Dis. 2014;14:69.

14. Hakizimana E, Cyubahiro B, Rukundo A, Kabayiza A, Mutabazi A, Beach R, et al. Monitoring long-lasting insecticidal net (LLIN) durability to validate net serviceable life assumptions, in Rwanda. Malar J. 2014;13:344.

15. Koenker H, Kilian A, de Beyl CZ, Onyefunafoa EO, Selby RA, Abeku T, et al. What happens to lost nets: a multi-country analysis of reasons for LLIN attrition using 14 household surveys in four countries. Malar J. 2014;13:464.

16. Kilian A, Koenker H, Obi E, Selby RA, Fotheringham M, Lynch M. Field durability of the same type of long-lasting insecticidal net varies between regions in Nigeria due to differences in household behaviour and living conditions. Malar J. 2015;14:123.

17. Mabaso ML, Sharp B, Lengeler C. Historical review of malarial control in southern African with emphasis on the use of indoor residual housespraying. Trop Med Int Health. 2004;9:846-56.

18. WHO. Indoor residual spraying: an operational manual for IRS for malaria transmission, control and elimination. Geneva: World Health Organization; 2013.

19. White MT, Conteh L, Cibulskis R, Ghani AC. Costs and cost-effectiveness of malaria control interventions - a systematic review. Malar J. 2011;10:337.

20. Killeen GF. Characterizing, controlling and eliminating residual malaria transmission. Malar J. 2014;13:330.

21. Corbel V, Akogbeto M, Damien GB, Djenontin A, Chandre F, Rogier C, et al Combination of malaria vector control interventions in pyrethroid resistance area in Benin: a cluster randomised controlled trial. Lancet Infect Dis, 2012;12:617-26.

22. Oxborough RM, N'Guessan R, Kitau J, Tungu PK, Malone D, Mosha FW, et al. A new class of insecticide for malaria vector control: evaluation of mosquito nets treated singly with indoxacarb (oxadiazine) or with a pyrethroid mixture against Anopheles gambiae and Culex quinquefasciatus. Malar J. 2015;14:353.

23. Oxborough RM, N'Guessan R, Jones R, Kitau J, Ngufor C, Malone D, et al. The activity of the pyrrole insecticide chlorfenapyr in mosquito bioassay: towards a more rational testing and screening of non-neurotoxic insecticides for malaria vector control. Malar J. 2015;14:124.

24. Ngufor C, N'Guessan R, Fagbohoun J, Odjo A, Malone D, Akogbeto M, et al. Olyset Duo ${ }^{\circledR}$ (a pyriproxyfen and permethrin mixture net): an experimental hut trial against pyrethroid resistant Anopheles gambiae and Culex quinquefasciatus in Southern Benin. PLoS ONE. 2014;9:e93603.

25. N'Guessan R, Ngufor C, Kudom AA, Boko P, Odjo A, Malone D, et al. Mosquito nets treated with a mixture of chlorfenapyr and alphacypermethrin control pyrethroid resistant Anopheles gambiae and Culex quinquefasciatus mosquitoes in West Africa. PLoS ONE. 2014;9:e87710.

26. Oxborough RM, Kitau J, Jones R, Mosha FW, Rowland MW. Experimental hut and bioassay evaluation of the residual activity of a polymerenhanced suspension concentrate (SC-PE) formulation of deltamethrin for IRS use in the control of Anopheles arabiensis. Parasites Vectors. $2014 ; 7: 454$

27. Oxborough RM, Kitau J, Jones R, Feston E, Matowo J, Mosha FW, et al. Long-lasting control of Anopheles arabiensis by a single spray application of micro-encapsulated pirimiphos-methyl (Actellic ${ }^{\circledR} 300$ CS). Malar J. 2014;13:37.

28. Stewart ZP, Oxborough RM, Tungu PK, Kirby MJ, Rowland MW, Irish SR Indoor application of attractive toxic sugar bait (ATSB) in combination with mosquito nets for control of pyrethroid-resistant mosquitoes. PLoS ONE. 2013;8:e84168.

29. Qualls WA, Muller GC, Traore SF, Traore MM, Arheart KL, Doumbia S, et al. Indoor use of attractive toxic sugar bait (ATSB) to effectively control malaria vectors in Mali, West Africa. Malar J. 2015;14:301.

30. Kitau J, Oxborough R, Kaye A, Chen-Hussey V, Isaacs E, Matowo J, et al. Laboratory and experimental hut evaluation of a long-lasting insecticide treated blanket for protection against mosquitoes. Parasites Vectors. 2014;7:129. 
31. Kirby MJ, Ameh D, Bottomley C, Green C, Jawara M, Milligan PJ, et al. Effect of two different house screening interventions on exposure to malaria vectors and on anaemia in children in The Gambia: a randomised controlled trial. Lancet. 2009;374:998-1009.

32. Tusting LS, Ippolito MM, Willey BA, Kleinschmidt I, Dorsey G, Gosling RD, et al. The evidence for improving housing to reduce malaria: a systematic review and meta-analysis. Malar J. 2015;14:209.

33. Roll Back Malaria. Consensus statement on housing and malaria. Geneva: Roll Back Malaria Housing and Malaria Work Stream; 2015.

34. Hewitt S, Rowland M, Muhammad N, Kamal M, Kemp E. Pyrethroidsprayed tents for malaria control: an entomological evaluation in Pakistan. Med Vet Entomol. 1995;9:344-52.

35. Bouma MJ, Parvez SD, Nesbit R, Winkler AM. Malaria control using permethrin applied to tents of nomadic Afghan refugees in northern Pakistan. Bull World Health Organ. 1996;74:413-21.

36. Graham K, Mohammad N, Rehman H, Nazari A, Ahmad M, Kamal M, et al. Insecticide-treated plastic tarpaulins for control of malaria vectors in refugee camps. Med Vet Entomol. 2002;16:404-8.

37. Graham K, Rehman H, Ahmad M, Kamal M, Khan I, Rowland M. Tents pre-treated with insecticide for malaria control in refugee camps: an entomological evaluation. Malar J. 2004;3:25.

38. Diabate A, Chandre F, Rowland M, N'Guessan R, Duchon S, Dabire KR, et al. The indoor use of plastic sheeting pre-impregnated with insecticide for control of malaria vectors. Trop Med Int Health. 2006;11:597-603.

39. Djènontin A, Chabi J, Baldet T, Irish S, Pennetier C, Hougard JM, et al. Managing insecticide resistance in malaria vectors by combining carbamatetreated plastic wall sheeting and pyrethroid-treated bed nets. Malar J. 2009;8:233.

40. Sharma SK, Upadhyay AK, Hague MA, Tyagi PK, Mohanty SS, Mittal PK, et al. Field evaluation of ZeroFly - an insecticide incorporated plastic sheeting against malaria vectors \& its impact on malaria transmission in tribal area of northern Orissa. Indian J Med Res. 2009;130:458-66.

41. Djènontin A, Chandre F, Dabire KR, Chabi J, N'quessan R, Baldet T, et al. Indoor use of plastic sheeting impregnated with carbamate combined with long-lasting insecticidal mosquito nets for the control of pyrethroidresistant malaria vectors. Am J Trop Med Hyg. 2010;83:266-70.

42. Chandre F, Dabire RK, Hougard JM, Djogbenou LS, Irish SR, Rowland M, et al. Field efficacy of pyrethroid treated plastic sheeting (durable lining) in combination with long lasting insecticidal nets against malaria vectors. Parasites Vectors. 2010;3:65

43. Mittal PK, Sreehari U, Razdan RK, Dash AP. Evaluation of the impact of ZeroFly ${ }^{\circledR}$, an insecticide incorporated plastic sheeting on malaria incidence in two temporary labour shelters in India. J Vector Borne Dis. 2011;48:138-43.

44. Burns M, Rowland M, N'guessan R, Carneiro I, Beeche A, Ruiz SS, et al. Insecticide-treated plastic sheeting for emergency malaria prevention and shelter among displaced populations: an observational cohort study in a refugee setting in Sierra Leone. Am J Trop Med Hyg. 2012;87:242-50.

45. Brosseau L, Drame PM, Besnard P, Toto JC, Foumane V, Le Mire J, et al. Human antibody response to Anopheles saliva for comparing the efficacy of three malaria vector control methods in Balombo, Angola. PLoS ONE. 2012;7:e44189.

46. Ngufor C, Tungu P, Malima R, Kirby M, Kisinza W, Rowland M. Insecticidetreated net wall hangings for malaria vector control: an experimental hut study in north-eastern Tanzania. Malar J. 2014;13:336.

47. Ngufor C, Chouaibou M, Tchicaya E, Loukou B, Kesse N, N'Guessan R, et al. Combining organophosphate-treated wall linings and long-lasting insecticidal nets fails to provide additional control over long-lasting insecticidal nets alone against multiple insecticide-resistant Anopheles gambiae in Côte d'Ivoire: an experimental hut trial. Malar J. 2014;13:396.

48. Ngufor C, Tchicaya E, Koudou B, N'Fale S, Dabire R, Johnson P, et al. Combining organophosphate treated wall linings and long-lasting insecticidal nets for improved control of pyrethroid resistant Anopheles gambiae. PLOS ONE. 2014;9:e83897.

49. WHO. Global plan for insecticide resistance management in malaria vectors. Geneva: World Health Organization; 2012.

50. Darriet F, N'Guessan R, Hougard JM, Traore-Lamizana M, Carnevale P. An experimental tool essential for the evaluation of insecticides: the testing huts. Bull Soc Pathol Exot. 2002;95:299-303 (in French).

51. Smith A. A verandah-trap hut for studying the house-frequenting habits of mosquitoes and for assessing insecticides. I. A description of the verandah-trap hut and of studies on the egress of Anopheles gambiae Giles and Mansonia uniformis (Theo.) from an untreated hut. Bull Entomol Res. 1965;56:161-9.

52. Messenger LA, Miller NP, Adeogun AO, Awolola TS, Rowland M. The development of insecticide-treated durable wall lining for malaria control: insights from rural and urban populations in Angola and Nigeria. Malar J. 2012;11:332.

53. Messenger LA, Matias A, Manana AN, Stiles-Ocran JB, Knowles S, Boakye DA, et al. Multicentre studies of insecticide-treated durable wall lining in Africa and South-East Asia: entomological efficacy and household acceptability during one year of field use. Malar J. 2012;11:358.

54. Kweka EJ, Lee MC, Mwang'onde BJ, Tenu F, Munga S, Kimaro EE, et al. Bioefficacy of deltamethrin based durable wall lining against wild populations of Anopheles gambiae s.I. in Northern Tanzania. BMC Res Notes. 2017;10:92.

55. Mtove G, Mugasa JP, Messenger LA, Malima RC, Mangesho P, Magogo F, et al. The effectiveness of non-pyrethroid insecticide-treated durable wall lining to control malaria in rural Tanzania: study protocol for a two-armed cluster randomized trial. BMC Public Health. 2016;16:633.

56. Edi CV, Djogbenou L, Jenkins AM, Regna K, Muskavitch MA, Poupardin $\mathrm{R}$, et al. CYP6 P450 enzymes and ACE-1 duplication produce extreme and multiple insecticide resistance in the malaria mosquito Anopheles gambiae. PLoS Genet. 2014;10:e1004236.

57. Pulford J, Tandrapah A, Atikinson JA, Kaupa B, Russell T, Hetzel MW. Feasibility and acceptability of insecticide-treated plastic sheeting (ITPS) for vector control in Papua New Guinea. Malar J. 2012;11:342.

58. Kuadima JJ, Timinao L, Naidi L, Tandrapah A, Hetzel MW, Czeher C, et al. Long-term acceptability, durability and bio-efficacy of ZeroVector ${ }^{\circledR}$ durable lining for vector control in Papua New Guinea. Malar J. 2017;16:93.

59. Kruger T, Sibanda MM, Focke WW, Bornman MS, de Jager C. Acceptability and effectiveness of a monofilament, polyethylene insecticide-treated wall lining for malaria control after six months in dwellings in Vhembe District, Limpopo Province, South Africa. Malar J. 2015;14:485.

60. Liu JX, Bousema T, Zelman B, Gesase S, Hashim R, Maxwell C, et al. Is housing quality associated with malaria incidence among young children and mosquito vector numbers? Evidence from Korogwe, Tanzania. PLoS ONE. 2014;9:e87358

61. Wanzirah H, Tusting LS, Arinaitwe E, Katureebe A, Maxwell K, Rek J, et al. Mind the gap: house construction and the risk of malaria in Ugandan children. PLOS ONE. 2015;10:e0117396.

62. Messenger LA, Larsen ML, Thomas JH, Rowland M. Installation of insecticide-treated durable wall lining: evaluation of attachment materials and product durability under field conditions. Parasites Vectors. 2014;7:508.

63. Kolaczinski K, Kolaczinski J, Kilian A, Meek S. Extension of indoor residual spraying for malaria control into high transmission settings in Africa. Trans R Soc Trop Med Hyg. 2007;101:852-3.

64. Oxborough RM. Trends in US President's Malaria Initiative-funded indoor residual spray coverage and insecticide choice in sub-Saharan Africa (2008-2015): urgent need for affordable, long-lasting insecticides. Malar J. 2016;15:146.

65. Bousema T, Stresman G, Baidjoe AY, Bradley J, Knight P, Stone W, et al. The impact of hotspot-targeted interventions on malaria transmission in Rachuonyo South District in the Western Kenyan highlands: a clusterrandomized controlled trial. PLoS Med. 2016;13:e1001993.

66. WHO Expert Committee. Control of the leishmaniasis: report of a meeting of the WHO expert committee on the control of leishmaniases, Geneva, 22-26 March 2010. WHO Tech Rep Ser. 2010;949:1-186.

67. Picado A, Dash AP, Bhattacharya S, Boelaert M. Vector control interventions for visceral leishmaniasis elimination initiative in South Asia, 2005-2010. Indian J Med Res. 2012;136:22-31.

68. Picado A, Singh SP, Rijal S, Sundar S, Ostyn B, Chappuis F, et al. Longlasting insecticidal nets for prevention of Leishmania donovani infection in India and Nepal: paired cluster randomised trial. BMJ. 2010;341:c6760.

69. Mondal D, Das ML, Kumar V, Huda MM, Das P, Ghosh D, et al. Efficacy, safety and cost of insecticide treated wall lining, insecticide treated bed nets and indoor wall wash with lime for visceral leishmaniasis vector control in the Indian sub-continent: a multi-country cluster randomized controlled trial. PLoS Negl Trop Dis. 2016;10:e0004932.

70. Huda MM, Kumar V, Das ML, Ghosh D, Priyanka J, Das P, et al. Entomological efficacy of durable wall lining with reduced wall surface coverage for strengthening visceral leishmaniasis vector control in Bangladesh, India and Nepal. BMC Infect Dis. 2016;16:539. 
71. Bern C. Chagas' disease. N Engl J Med. 2015;373:456-66

72. Gürtler R. Sustainability of vector control strategies in the Gran Chaco Region: current challenges and possible approaches. Mem Inst Oswaldo Cruz. 2009;104(Suppl1):52-9.

73. Maloney KM, Ancca-Juarez J, Salazar R, Borrini-Mayori K, Niemierko M, Yukich JO, et al. Comparison of insecticidal paint and deltamethrin against Triatoma infestans (Hemiptera: Reduviidae) feeding and mortality in simulated natural conditions. J Vector Ecol. 2013;38:6-11.

74. Amelotti I, Catala SS, Gorla DE. Experimental evaluation of insecticidal paints against Triatoma infestans (Hemiptera: Reduviidae), under natural climatic conditions. Parasites Vectors. 2009;2:30.
75. Gorla DE, Ortiz RV, Catala SS. Control of rural house infestation by Triatoma infestans in the Bolivian Chaco using a microencapsulated insecticide formulation. Parasites Vectors. 2015;8:255

76. Alarico AG, Romero N, Hernandez L, Catala S, Gorla D. Residual effect of a microencapsulated formulation of organophosphates and piriproxifen on the mortality of deltamethrin resistant Triatoma infestans populations in rural houses of the Bolivian Chaco region. Mem Inst Oswaldo Cruz. 2010;105:752-6.

\section{Submit your next manuscript to BioMed Central and we will help you at every step:}

- We accept pre-submission inquiries

- Our selector tool helps you to find the most relevant journal

- We provide round the clock customer support

- Convenient online submission

- Thorough peer review

- Inclusion in PubMed and all major indexing services

- Maximum visibility for your research

Submit your manuscript at www.biomedcentral.com/submit 